\title{
Removal of methanol from air in a low-pH trickling monolith bioreactor
}

Yaomin Jin, María C. Veiga, Christian Kennes

Process Biochemistry, Volume 43, Issue 9, September 2008, Pages 925-931

DOI: $10.1016 /$ j.procbio.2008.04.019

\begin{abstract}
A novel ceramic monolith bioreactor colonized by a methanol-degrading culture was investigated in order to assess its suitability for waste gas treatment. The acidotolerant yeast Candida boidinii was identified as dominant organism in the biofilm. The culture was able to efficiently biodegrade methanol at a $\mathrm{pH}$ as low as 2, both in batch and in continuous bioreactor studies. Operational parameters that were considered include start-up of the bioreactor, methanol loading, mineralization of methanol, pressure drop and biofilm accumulation during steady-state operation. A high maximal elimination capacity of $234 \mathrm{~g} \mathrm{~m}^{-3} \mathrm{~h}^{-1}$ was reached, with more than $80 \%$ removal efficiency and complete conversion of methanol into biomass and end products. Removal efficiencies exceeding $90 \%$ were obtained up to loads of about $200 \mathrm{~g} \mathrm{~m}^{-3} \mathrm{~h}^{-1}$. Problems of excess biomass accumulation and pressure drop after long-term operation can easily be solved by temporarily increasing the liquid trickling rate. This is the first report on the treatment of methanol-polluted air in such a low-pH monolith bioreactor.
\end{abstract}

\section{Keywords}

Monolith; Acidotolerant microorganism; Mass transfer; Pressure drop; Volatile organic compound; Waste gas

\section{Introduction}

Biological treatment processes are emerging cost-effective and environmental-friendly technologies for treating large flow rates of gas streams with relatively low concentrations of pollutants [1] and [2]. Waste gases are purified by flowing through the biologically active material. Gas-phase contaminants transfered to a wet biofilm layer surrounding the support particles are aerobically degraded to carbon dioxide and water or precursors used to build up new biomass. Conventional biofilters are usually packed with natural carriers, such as compost, peat, wood chips or soil. They decay over time, causing compaction, clogging, short circuiting and increased headloss across the bed. This will increase capital and operation costs because of the need for frequent replacement of the packing, high energy consumption and a large footprint area. Therefore, new inert and synthetic packing materials have recently been developed for solving these problems. However, the addition of a nutritive aqueous phase is a prerequisite for optimal bioreactor performance with such new packing materials, since nutrients, essential for optimizing the microbial activity, are not naturally available in inert filter beds [3]. 
The monolith, which is widely used as catalyst support for gas treatment, e.g., cleaning of automotive exhaust gases and industrial off gases, can be tailored to meet the needs of a relatively inexpensive, light weight, inert, bioreactor packing that provides a high specific surface area to greatly increase the mass transfer rate [4]. The surface area of monolith packings ranges from a few hundreds to thousands $\mathrm{m}^{2}$ per $\mathrm{m}^{3}$, which is significantly more than the packing materials used in packed absorption towers. The latter usually have specific surface areas between 100 and $300 \mathrm{~m}^{2} \mathrm{~m}^{-3}$ [2]. Reactors using monolithic catalyst supports may be an attractive alternative to conventional multi-phase reactors and have been used in bioconversion and fermentation processes [4], [5], [6], [7] and [8]. In monolithic channels bubble-train or Taylor flow usually occur. The gas and liquid move through the channels as separate slugs approaching plug flow behavior. Between the gas bubble and the biocatalyst wall, a thin film is found, through which gas is readily transferred to the bio-catalytically active wall. This biofilm layer remains at the wall when the liquid slug passes by. Inside the liquid slug itself, a recirculation pattern is observed. This recirculation enhances transfer of gas from the caps of the bubble to the biocatalyst.

Ebrahimi et al. [9] suggested that the monolith may be a promising support material for biomass because of several potential advantages: (1) low pressure drop, (2) large pore size and large specific surface area, (3) thin walls, (4) better liquid distribution at low liquid flow rates, (5) high mechanical strength and (6) scaling up promises to be relatively easy compared to other reactor types.

In a recent study conducted in our laboratory, the potential of using the monolith bioreactor for environmental applications, in the field of biological waste gas treatment, was demonstrated for the first time [10]. It was observed that the monolith bioreactor readily supports biomass growth on its surface and successfully treats toluene-polluted air. However, clogging of the channels is a main challenge for long-term stable operation [10].

Common heterotrophs capable of consuming volatile organic compounds (VOCs) prefer neutral $\mathrm{pH}$ [11], although some researchers found that most fungi could grow on VOCs in highly acidic environments and are tolerant to pHs well below 4 [12], [13] and [14]. VOC-degrading bacteria have occasionally also been found to mineralize organic pollutants in relatively low-pH environments [15]. Pöland et al. [16] observed that the yield coefficient of biomass for acidophilic methanol utilizing bacteria is lower than the value of neutrophilic methanol utilizing bacteria. This property would be very useful for bioreactors treating waste gases due to reduced clogging problems as a result of the low biomass growth. A similar characteristic is found in thermophilic microorganisms which do generally generate less biomass than mesophilic ones, allowing to reduce pressure drop [17]. Besides, a few off-gases, such as those of pulp and paper industries, contain a complex mixture of $\mathrm{H}_{2} \mathrm{~S}$ and other reduced sulfur compounds (RSCs, such as dimethyl sulfide, dimethyl disulfide and methyl mercaptan), as well as volatile organic compounds (VOCs, such as methanol, terpenes, alcohols, phenol, ketones and formaldehyde) [18]. One problem encountered in the co-treatment of RSCs and VOCs is that the $\mathrm{pH}$ of the biofilm will drop when sulfur compounds are converted into sulfuric acid. The biological activity in the biofilter and VOC-degradation may then temporarily be inhibited by the rapid $\mathrm{pH}$ decline, thereby reducing the treatment effectiveness of VOCs and RSCs. Another problem with acid production is that acids degrade organic media, such as compost, and can open channels in some areas and 
cause compaction in others. Methanol is one of the 189 hazardous air pollutants in the Clean Air Act Amendments of 1990 (CAAA 90) Title III, an important chemical feedstock and industrial solvent, and a major air emission from pulp and paper as well as wood industries. It is a normal by-product of the pulping of wood fibre and accounts for about $70 \%$ of the total toxic chemical release in the industry, based on the EPA's Toxic Release Inventory (TRI) list. Although methanol is very hydrophilic, it is released into the atmosphere from several sources such as evaporators and brown stock washers due to the nature of the processes in these sources and their relatively high temperature, as well as methanol's low vapor pressure. In our previous work, a low-pH single stage biotrickling filter was successfully designed for the co-treatment of $\mathrm{H}_{2} \mathrm{~S}$ and methanol [19]. The dominant acidotolerant culture could efficiently degrade methanol at pH 2.

In order to avoid the afore described problems, the following measures were taken in the present study: (1) use of a trickling bioreactor allowing a better control of operational conditions; (2) use of monolith packing and (3) inoculation of an acidotolerant yeast-dominant culture. The goal of this study was then to investigate the biotreatment of methanol-polluted air using a novel monolith trickling bioreactor, with an acidotolerant culture immobilized on the channel surface of the monolith, and to determine the operating parameters that affect the performance of such a system.

\section{Material and methods}

\subsection{Medium composition}

Batch experiments and growth of the inoculum were undertaken with an aqueous culture medium containing (per liter): $2 \mathrm{~g} \mathrm{KH}_{2} \mathrm{PO}_{4}, 2 \mathrm{~g} \mathrm{~K}_{2} \mathrm{HPO}_{4}, 0.4 \mathrm{~g} \mathrm{NH} \mathrm{NH}_{4} \mathrm{Cl} 0.2 \mathrm{~g}$ $\mathrm{MgCl}_{2} \cdot 6 \mathrm{H}_{2} \mathrm{O}$ and $0.01 \mathrm{~g} \mathrm{FeSO}_{4} \cdot 7 \mathrm{H}_{2} \mathrm{O}$. The original $\mathrm{pH}$ of the culture medium was 6.8. In the batch experiments, the $\mathrm{pH}$ of the medium was adjusted to the desired values by adding either $1 \mathrm{M} \mathrm{H}_{2} \mathrm{SO}_{4}$ or $1 \mathrm{M} \mathrm{NaOH}$. Similarly, the $\mathrm{pH}$ of the medium used in the continuous monolith reactor was adjusted to 2 .

\subsection{Batch experiments}

All batch assays were performed at least in duplicate, with the corresponding controls, under sterile conditions. The mineral medium and vials were autoclaved at $120^{\circ} \mathrm{C}$ for 20 min. Both uninoculated media (called "blanks") and inoculated autoclaved vials (called "controls"') were used. The mineral medium described above $(100 \mathrm{ml})$ was introduced into 500-ml bottles closed with Viton septa and screw caps, and maintained at $30^{\circ} \mathrm{C}$. Thirty microliter of methanol was added into each bottle as the sole carbon and energy source. A yeast-dominant enriched culture was used as inoculum. It was obtained from a previous experiment done with a biotrickling filter co-treating $\mathrm{H}_{2} \mathrm{~S}$ and $\mathrm{CH}_{3} \mathrm{OH}$ polluted air [19]. Stock cultures were grown on methanol in a mineral medium until they reached an optical density of 0.24 at $660 \mathrm{~nm}$. After homogenization, $15 \mathrm{ml}$ of that stock culture, corresponding to $5.8 \mathrm{mg}$ dry biomass, was inoculated into the bottles for the biodegradation assays, allowing all experiments to start with identical biomass concentrations and allowing the calculation of specific biodegradation rates (micrograms of methanol per gram of biomass per hour). 


\subsection{Continuous bioreactor studies}

The schematic of the bioreactor used in this study is shown in Fig. 1. The monolith column was placed in a transparent methacrylate box. A rubber ring and silicone glue were used to fit the monolith inside the methacrylate box in order to prevent a by-pass of the gas and liquid between the monolith and the walls of the box. A large stream of compressed air was humidified up to $97 \%$ relative humidity by passing it through a closed carboy containing water. A small stream of air was bubbled through a vial containing pure methanol and was mixed with the larger humidified gas stream as described earlier [20]. This arrangement allowed to vary the flow rates and the vapor concentrations independently by directing a larger or smaller flow of air through the methanol solvent. Gas-phase methanol concentrations ranging from 0 to $2780 \mathrm{mg} \mathrm{m}^{-3}$ were obtained by adjusting the flow rates of the different gas streams. The resulting synthetic waste gas was introduced through the top of the reactor in co-current flow. Sampling ports allowed to determine the methanol concentration at the inlet and the outlet of the bioreactor. The monolith bioreactor was installed in an exhaust hood and operated at ambient temperature $\left(20-22^{\circ} \mathrm{C}\right)$.

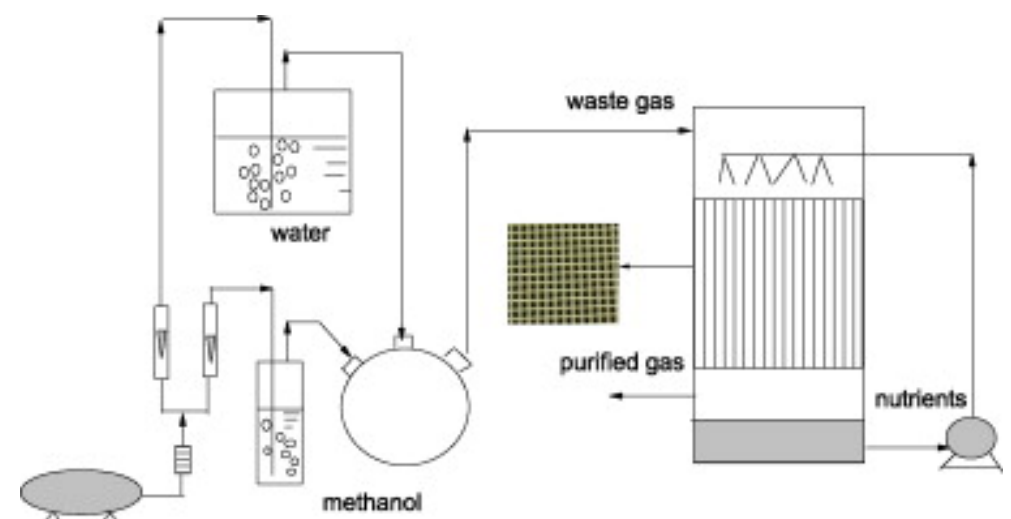

Fig. 1.

Schematic of the monolith bioreactor.

The inoculum used for the continuous reactor was an enriched yeast-dominant culture, obtained from the batch experiments. Before inoculation of the bioreactor, the acidotolerant methanol-degrading culture was grown aerobically, at $30{ }^{\circ} \mathrm{C}$, in $500 \mathrm{ml}$ shaken Erlenmeyer flasks containing $100 \mathrm{ml}$ of sterilized nutrient medium with $0.15 \%$ (v/v) methanol, at $\mathrm{pH} 2$. After $24-48 \mathrm{~h}$ of growth, the cells were harvested by centrifugation at $5000 \mathrm{rpm}$ for $20 \mathrm{~min}$ and re-suspended in $1 \mathrm{l}$ fresh nutrient medium to be used as inoculum for the continuous bioreactor. The nutrient solution was pumped from the sedimentation basin through a peristaltic pump (model 323E/D, WatsonMarlow Limited, Falmouth Cornwall, England) into a distribution manifold. The flow rate of the trickling liquid was $1 \mathrm{l} \mathrm{h}^{-1}$, unless otherwise specified. The nutrient solution of the bioreactor was renewed daily. A sieve screen located above the monolith allowed uniform nutrient distribution over the top of the monolith. Methanol-polluted air was fed continuously in a downflow mode. After 5 days continuous recirculation of a methanol containing solution over the packing material, a visible biofilm developed on the surface of the square channels of the monolith. The reactor was run for a period of more than 6 months. During the first 10 days of the start-up period, the inlet concentration was increased from 12 to $467 \mathrm{mg} \mathrm{m}^{-3}$ for culture acclimation. In order to confirm the steady state, the bioreactor was stabilized for the following 10 days with an 
inlet concentration of $200 \mathrm{mg} \mathrm{m}^{-3}$. Afterwards, experiments on the effect of the inlet concentration, inlet load, and mineralization of methanol were conducted at inlet methanol concentrations progressively increased from 467 to about $2780 \mathrm{mg} \mathrm{m}^{-3}$. During the experimental period, each operating condition was maintained for at least a few days of steady-state. A subsequent change was only performed after the performance of the previous stage had remained stable for at least 3 days.

\subsection{Monolith support}

The ceramic monolith packing is shown in Fig. 1. It has the following characteristicsgeometry: honeycomb with square ducts; length: $150 \mathrm{~mm}$; cross-section: $100 \mathrm{~mm} \times 100 \mathrm{~mm}$; number of channels: $26 \times 26$; channel width: $3.0 \mathrm{~mm}$; weight: $850 \mathrm{~kg} \mathrm{~m}^{-3}$; geometric surface: $800 \mathrm{~m}^{2} \mathrm{~m}^{-3}$; voids fraction: $64 \%$. Details of the composition and the preparation procedure of the support used in this work are proprietary information of Rauschert Verfahrenstechnik GmbH (Germany).

\subsection{Analytical methods}

Determination of methanol removal in flasks in batch assays was carried out by measuring methanol concentrations in the headspace gas. Gas samples of $100 \mu \mathrm{l}$ were taken intermittently with a gastight Hamilton syringe. The concentration of methanol in the liquid phase could be estimated by means of Henry's constant. The concentration of methanol in the gas phase was measured by gas chromatography using a HewlettPackard 5890 series II gas chromatograph (GC) equipped with a flame ionization detector (FID) (flow rates: $\mathrm{H}_{2} 30 \mathrm{ml} \mathrm{min}^{-1}$, air $300 \mathrm{ml} \mathrm{min}^{-1}$ ). The inlet and outlet streams were sampled. The GC was equipped with a 50-m TRACER column (TRWAX, internal diameter $0.32 \mathrm{~mm}$, film thickness $1.2 \mu \mathrm{m}$ ) and Helium was used as the carrier gas (flow rate $2.0 \mathrm{ml} \mathrm{min}{ }^{-1}$ ). The methanol concentration was determined at the oven temperature of $175^{\circ} \mathrm{C}$. The FID's temperature was $250{ }^{\circ} \mathrm{C}$. Similarly, the $\mathrm{CO}_{2}$ concentration was measured using another Hewlett-Packard 5890 series II GC equipped with a thermal conductivity detector (TCD). The $\mathrm{CO}_{2}$ concentrations were determined at an injection temperature of $90^{\circ} \mathrm{C}$ and an oven temperature of $25^{\circ} \mathrm{C}$ and using a TCD at $100{ }^{\circ} \mathrm{C}$. From the difference between the inlet and outlet values of a manometer connected to the inlet and outlet ports of the reactor, pressure drop was calculated and normalized per meter packing height.

Biomass weight was estimated by measuring the optical density (OD), and a standard calibration line was plotted based on the relationship between dry weight and OD. The absorbance of the liquid cultures was measured by using a spectrophotometer (Hitachi, Model U-2001UV/vis; Pacisa \& Giralt, Madrid, Spain). Biomass was also determined gravimetrically in batch tests by filtering a known volume of culture sample through $0.2 \mu \mathrm{m}$ Millipore filter papers. After washing with distilled water, the filter paper was dried to constant mass at $105^{\circ} \mathrm{C}$ [21]. A Crison model $507 \mathrm{pH}$ meter, connected to an Ingold electrode was used for measuring the $\mathrm{pH}$. 


\section{Results}

\subsection{Batch assays}

Initially, methanol degradation and biomass growth were slow. The slight increase of methanol concentration in the gas phase just after adding the substrate was probably due to the volatilization of methanol from the liquid phase and to the time needed to reach equilibrium conditions between the gas and liquid phases (Fig. 2). Afterwards, the microbial culture entered the log phase and the degradation rate of methanol increased sharply (Fig. 2). Around 55\% of the methanol added to the vials was recovered as carbon dioxide on a molar-basis. The yield coefficient of biomass on methanol, $Y_{\mathrm{M}}$, reached $0.345 \mathrm{~kg}$ dry biomass per $\mathrm{kg}$ methanol consumed from the shake-flask experiments at $\mathrm{pH} 2$.

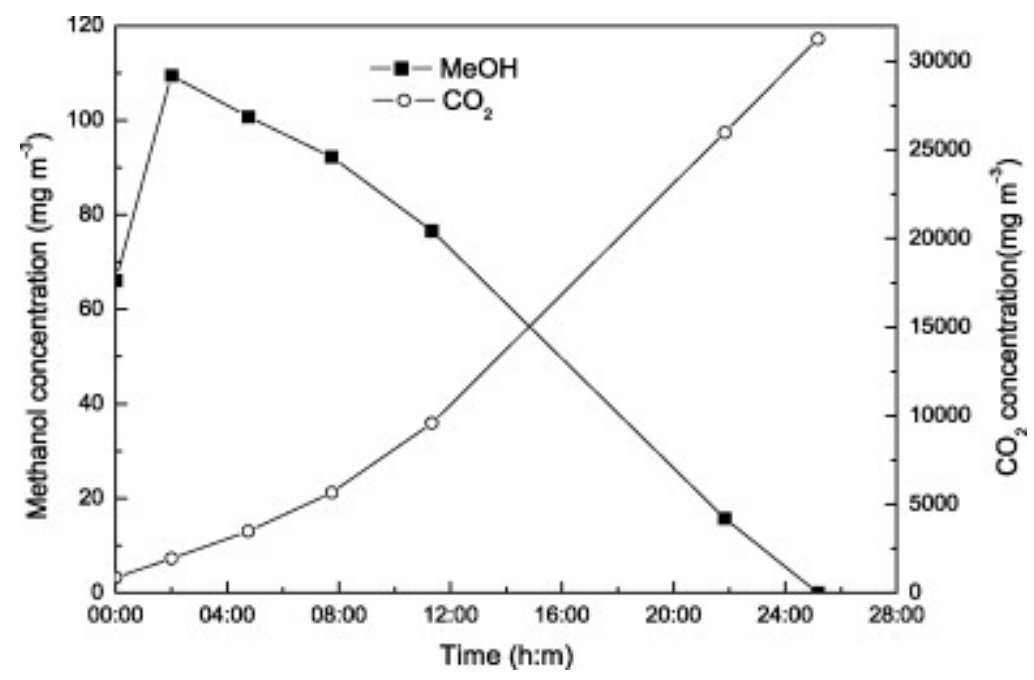

Fig. 2.

Biodegradation of methanol and carbon dioxide production at $\mathrm{pH} 2$.

\subsection{Effect of $\mathrm{pH}$ on the biodegradation of methanol}

The $\mathrm{pH}$ value of the solution exerts a marked influence on the vital activities of microorganisms, and there is usually an optimum range that maximizes the biological performance. A set of batch experiments was undertaken with the acidotolerant biomass at different $\mathrm{pH}$ values between 2 and 7 . The $\mathrm{pH}$ shift from the initial values was less than 0.1 unit in all these batch experiments. The temperature was maintained at $30{ }^{\circ} \mathrm{C}$. Although slightly lower substrate degradation rates and $\mathrm{CO}_{2}$ production rates were observed at the extreme $\mathrm{pH}$ values of 2 and 7, methanol was degraded at rather similar rates over the whole $\mathrm{pH}$ range (Fig. 3). The results showed that there is thus no big difference in degradation rates, irrespective of the $\mathrm{pH}$. Enrichments on solid medium at $\mathrm{pH} 2$ and observations under the microscope showed that the dominant organism was a yeast, isolated on plates. The isolated strain was identified as Candida boidinii and appeared to be able to biodegrade methanol in pure liquid culture at $\mathrm{pH} 2$. Considering the common co-existence of methanol and RSCs in waste gases, the $\mathrm{pH}$ was maintained around 2 in the following continuous bioreactor experiments. 



Fig. 3.

Methanol and carbon dioxide concentrations during biodegradation assays at different initial pH. (a) Methanol and (b) $\mathrm{CO}_{2}$.

\subsection{Start-up of the continuous monolith bioreactor}

The preliminary studies described above demonstrated that the acidotolerant culture is capable of efficiently degrading methanol at low $\mathrm{pH}$. Therefore, the $\mathrm{pH}$ of the trickling nutrient solution used in the monolith reactor was maintained at 2 in order to get similar $\mathrm{pH}$ conditions as in actual situations and as in a trickling biofilter used before for the cotreatment of methanol and $\mathrm{H}_{2} \mathrm{~S}$ [19]. Removal efficiencies above 90\% were reached already on the first days of operation. It is well known that seeding an adapted culture allows a very fast start-up [2]. During the first 10 days of the experiment, removal efficiencies of $74-100 \%$ could be maintained while quickly increasing the inlet concentration from 12 to $467 \mathrm{mg} \mathrm{m}^{-3}$ (Fig. 4). After this start-up period, the inlet 
concentration was kept at $200 \mathrm{mg} \mathrm{m}^{-3}$ with an EBRT of $30 \mathrm{~s}$, reaching an elimination capacity of $30 \mathrm{~g} \mathrm{~m}^{-3} \mathrm{~h}^{-1}$ at that time, while maintaining the removal efficiency above 95\% (Fig. 4).

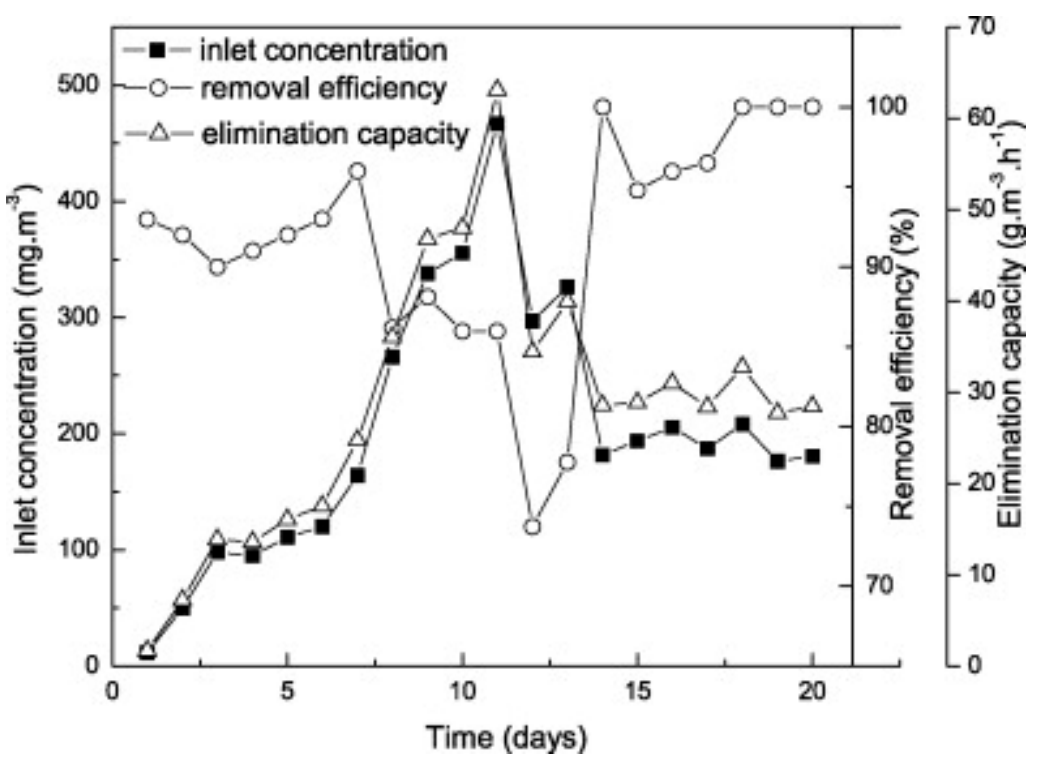

Fig. 4.

Methanol inlet concentration, removal efficiency and elimination capacity during the acclimation phase of the bioreactor studies.

\subsection{Effect of the inlet concentration and methanol load}

After the efficiency of the bioreactor had been stable for 10 more days, the inlet methanol concentration was progressively increased from 467 to about $2780 \mathrm{mg} \mathrm{m}^{-3}$, in order to evaluate the suitability of this system to treat fluctuating and high methanol concentrations in waste gases.

The dependence of the degree of conversion on the inlet methanol concentration in the waste gas is plotted in Fig. 5. Within the range of methanol concentrations tested, a slow linear decrease of the degree of conversion was observed when increasing the methanol concentration up to about $2780 \mathrm{mg} \mathrm{m}^{-3}$. 


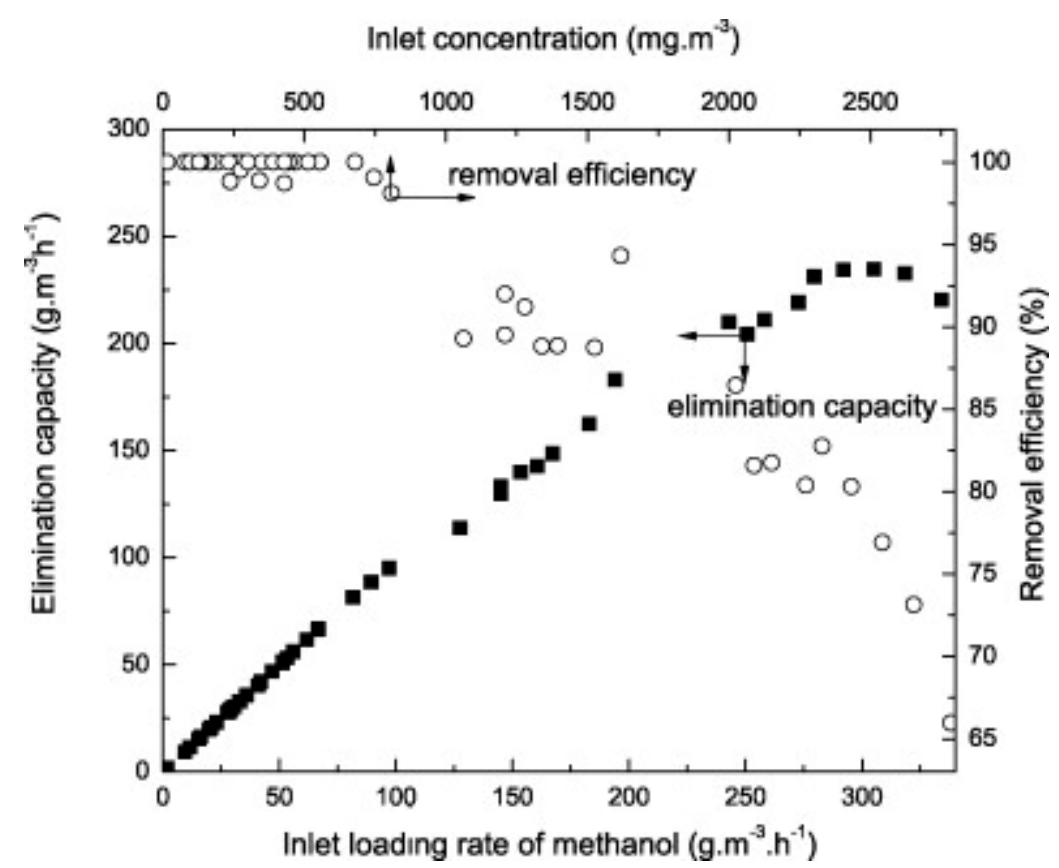

Fig. 5.

Dependence of removal efficiency on the inlet methanol concentration as well as elimination capacity on the inlet methanol load.

The elimination capacity of the bioreactor was calculated using the gas-phase methanol concentration data shown in Fig. 5. The methanol inlet load, which was defined as the amount of methanol fed per unit time and per unit volume of reactor, can affect the removal efficiency significantly. When the inlet load of methanol was increased from 15.6 to $94 \mathrm{~g} \mathrm{~m}^{-3} \mathrm{~h}^{-1}$, the removal efficiency remained around $98 \%$ (Fig. 5), but when the inlet load was further increased from 94 to $187 \mathrm{~g} \mathrm{~m}^{-3} \mathrm{~h}^{-1}$, the removal efficiency decreased to near $90 \%$. When the inlet methanol load was further increased above $250 \mathrm{~g} \mathrm{~m}^{-3} \mathrm{~h}^{-1}$, the elimination capacity reached its maximum value of $234 \mathrm{~g} \mathrm{~m}^{-3} \mathrm{~h}^{-1}$, with a removal efficiency still above $80 \%$ (Fig. 5).

\subsection{Mineralization of methanol to $\mathrm{CO}_{2}$ in the monolith reactor}

In gas-phase bioreactors the complete conversion of methanol under aerobic conditions yields carbon dioxide, water and biomass. Hence, monitoring the carbon dioxide concentration in the gas phase provides valuable information on the performance of the bioreactor and on the extent of mineralization of the pollutant. In order to solve environmental problems it is important to reach a complete biodegradation of pollutants into end products. The ratio of daily measurements of the carbon dioxide production and removal of methanol are summarized in Fig. 6. A linear correlation was found between the concentration of methanol removed and $\mathrm{CO}_{2}$ production. The equation of the line shown in Fig. 6 is basically $y=0.51 x$. Thus, the slope of this line is 0.51 indicating that the average ratio of the measured molar $\mathrm{CO}_{2}$ production to molar methanol removal was equal to 0.51 with a correlation coefficient of 0.99 . The amount methanol recovered as carbon dioxide was thus $51 \%$ on a molar basis. 


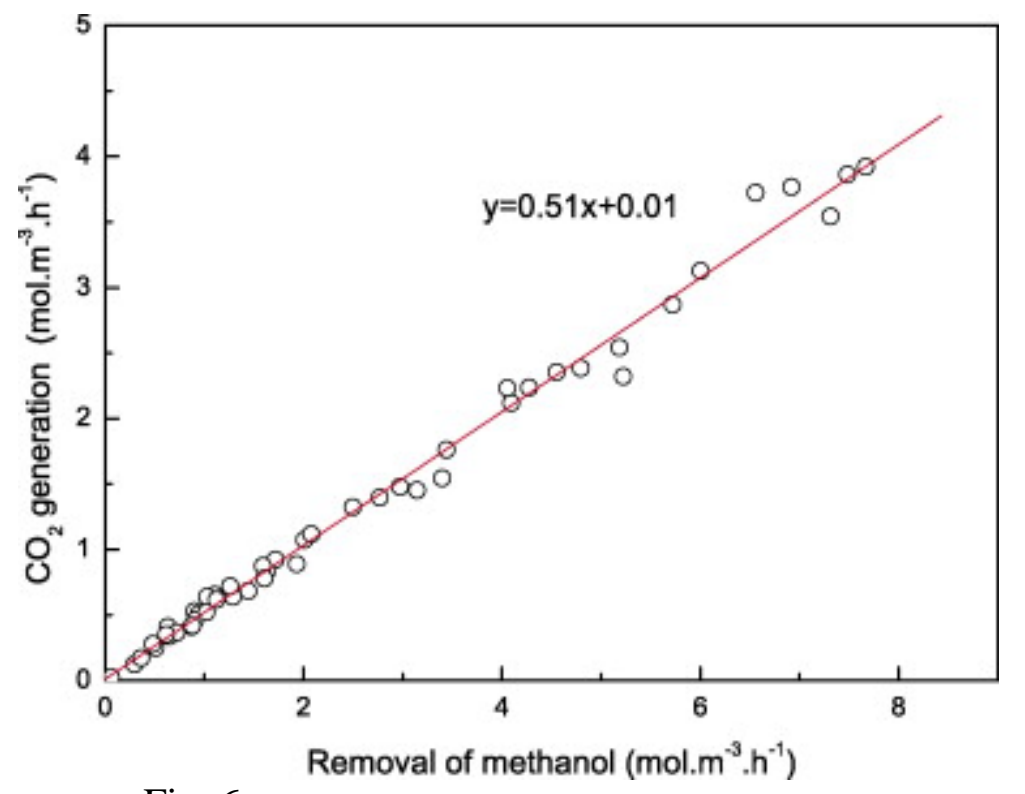

Fig. 6.

Carbon dioxide produced vs. elimination capacity of methanol.

\subsection{Pressure drop and biofilm growth in the monolith channels}

The pressure drop is a key aspect of a bioreactor's performance. It affects the energy consumption of the blower, which contributes most to the operation costs. The variations of the pressure drop in the monolith bioreactor are shown in Fig. 7. The pressure drop across the bioreactor indicates that biomass accumulation was relatively insignificant until day 50 of operation. It remained around $6 \mathrm{~mm} \mathrm{H}_{2} \mathrm{O} \mathrm{m}^{-1}$ after 35 days of operation. On day 60 of this operational period, the inlet loading rate of methanol was increased from 75 to $150 \mathrm{~g} \mathrm{~m}^{-3} \mathrm{~h}^{-1}$. This high load of methanol enhanced excess biomass growth causing clogging of the channels. Finally the accumulated biomass led to a dramatic increase in pressure drop across the bioreactor on day 75 (Fig. 7). Biomass accumulation can also be observed on the top view of the monolith packing shown in Fig. 8. Despite the somewhat lower biomass yield of most acidotolerant methanol degraders, maintaining high pollutant loads ends-up in excess biomass accumulation. In order to remove the excess biomass, a high liquid flow was used $\left(3 \mathrm{l} \mathrm{h}^{-1}\right)$ in order to generate shear forces and remove part of the biofilm attached on the channel-walls, allowing the pressure drop to return to its original value, around $6 \mathrm{~mm} \mathrm{H}_{2} \mathrm{O} \mathrm{m}^{-1}$. 


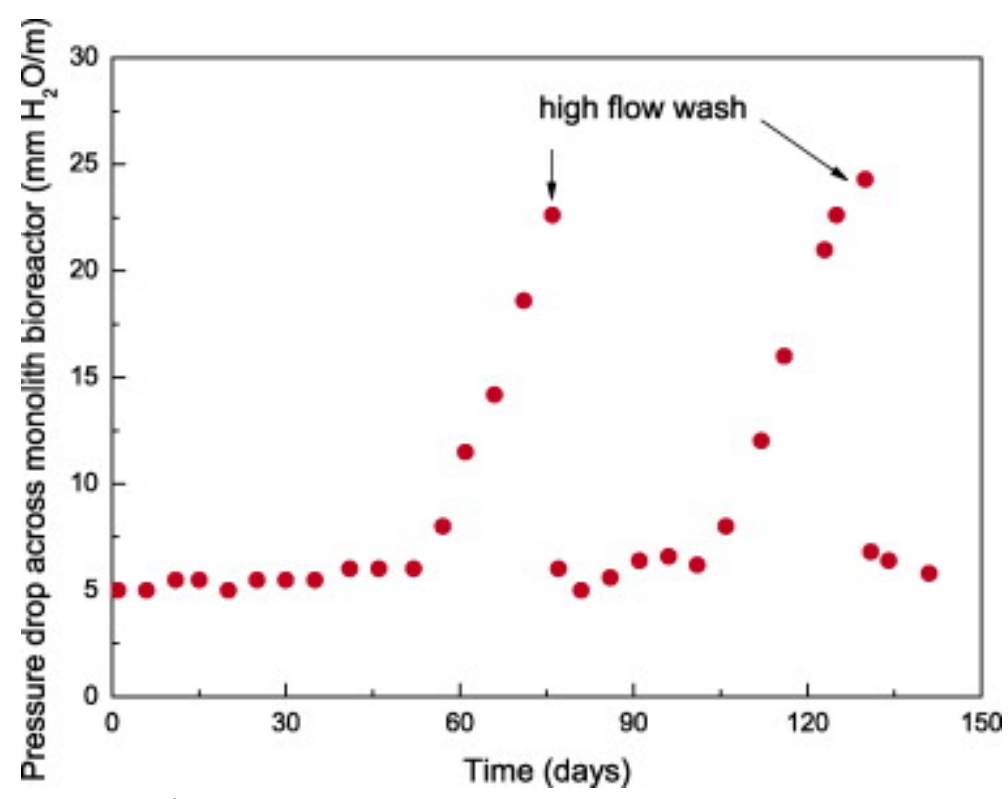

Fig. 7.

Development of pressure drop across the monolith bioreactor.

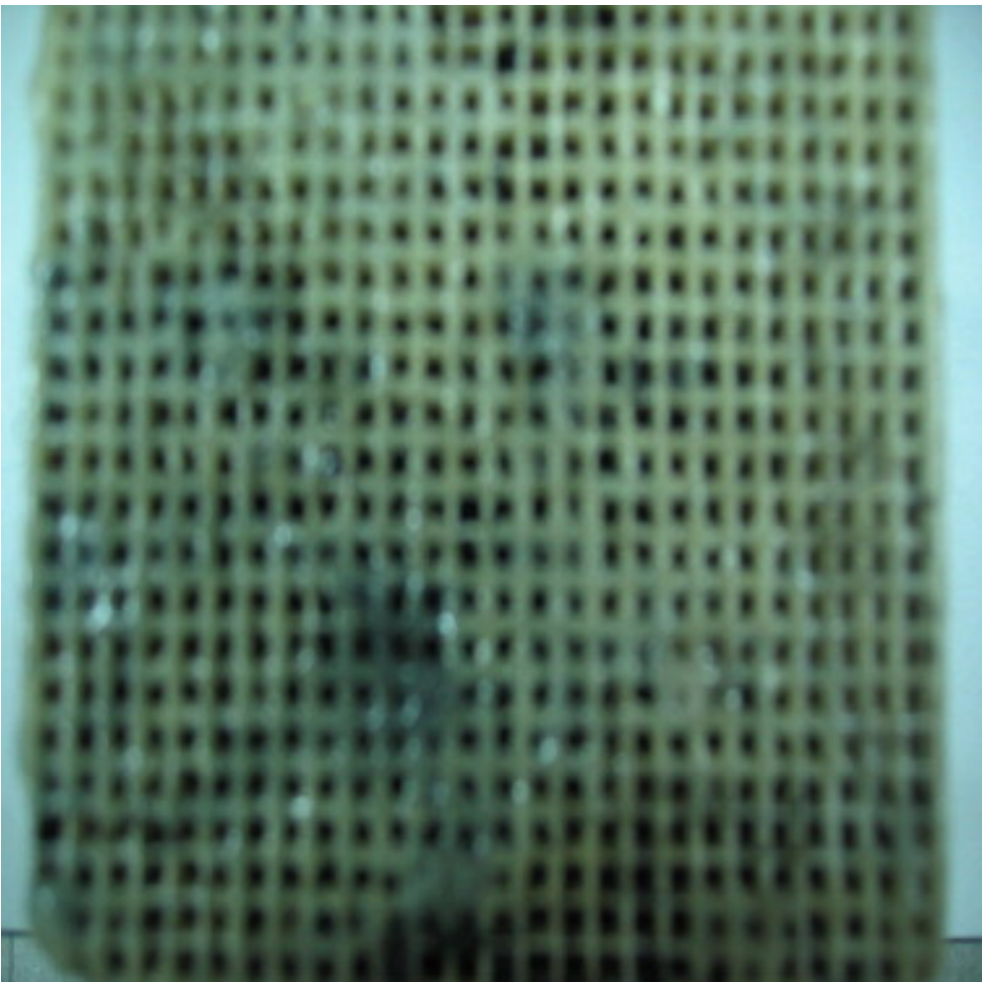

Fig. 8.

\section{$25 \mathrm{~mm}$}

Photograph of the biofilm developed in the square monolith channels.

After cleaning the monolith, the experiment was continued, and essentially the same stable operating time was obtained when applying the same loads. It sounds reasonable to postulate that regular washing of the monolith will allow for a long-term, stable operation. This can easily be done by temporarily increasing the flow rate of the 
trickling liquid. In a following experiment, fresh nutrient solution at $\mathrm{pH} 6.8$ was used instead of the recirculated nutrient solution at $\mathrm{pH} 2$, while keeping the other operational parameters the same, which resulted in a somewhat faster biomass accumulation.

\section{Discussion}

\subsection{Batch assays}

In the present study an acidotolerant microbial culture was shown to degrade methanol over the whole $\mathrm{pH}$ range $2-7$, at similar rates. Around $55 \%$ of the methanol added to the vials was recovered as carbon dioxide on a molar-basis (Fig. 2). This is similar to the values reported in the literature on biodegradation of methanol [22]. When biomass growth is taken into account, $0.553 \mathrm{~mol} \mathrm{CO}_{2}$ should be generated for each mol of methanol degraded, when using ammonium as nitrogen source, according to the following stoichiometric equation:

equation(1)

$\mathrm{CH}_{3} \mathrm{OH}+1.03 \mathrm{O}_{2}+0.0894 \mathrm{NH}_{4} \mathrm{Cl} \rightarrow 0.447 \mathrm{CH}_{1.8} \mathrm{O}_{0.5} \mathrm{~N}_{0.2}+1.732 \mathrm{H}_{2} \mathrm{O}+0.553 \mathrm{CO}_{2}+0.0$ $894 \mathrm{HCl}$

The experimental biomass yield coefficient on methanol reached $0.345 \mathrm{~kg} \mathrm{~kg}^{-1}$. Some authors have shown that the environmental conditions such as a high temperature [17] and [23] or a low $\mathrm{pH}$ [16], [24] and [25] may reduce biomass growth. Thus, acidophilic conditions would allow to limit biomass accumulation at high loads, while presumably maintaining high removal efficiencies. It has been reported in the literature that the growth yield, $Y$, of acidophilic methanol degrading bacteria is generally lower than for neutrophilic ones [16], [24] and [25]. Using neutrophilic bacteria typical yields are $Y=0.45-0.50$. With acidophilic bacteria the biomass yield usually reaches values of $Y=0.30-0.42$. Thus, our result $\left(0.345 \mathrm{~kg} \mathrm{~kg}^{-1}\right)$ agrees with the few values reported by others for such acidophilic microorganisms. This effect is, among others, probably due to the different pathways of methanol utilization as well as energy balances. Regarding the metabolic steps, neutrophilic bacteria utilize methanol via the hexulose phosphate pathway while acidophilic bacteria use the fructose bisphosphate variant of the hexulose phosphate pathway. In the case of methylotrophic yeasts, only one single metabolic pathway, i.e. the xylulose monophosphate cycle, has been found [26]. A lower production of biomass may be beneficial in continuous reactor operation, as it will slow down clogging problems and pressure drop increase.

The effect of $\mathrm{pH}$ on the biodegradation of methanol could be explained by the coexistence of mixed microbial populations, in which the acidotolerant microorganisms prefer a low $\mathrm{pH}$, while other microorganisms are more active at higher $\mathrm{pH}$ values. Besides, it has also been reported that some pure microbial strains may exhibit their metabolic activity over a relatively wide $\mathrm{pH}$ range of 3-4 units, although with variable growth and biodegradation rates [15]. It was shown that the yeast $C$. boidinii, dominant in the mixed culture, could degrade methanol at $\mathrm{pH} 2$ (manuscript in preparation). It is known that the use of methanol as sole carbon and energy sources is limited to very few yeast species, above all at such low $\mathrm{pH}$ value of 2 [26]. 


\subsection{Continuous monolith bioreactor}

The results indicate that the start-up phase was relatively short, which allowed increasing the load quite fast. The average degree of conversion of methanol to $\mathrm{CO}_{2}$ calculated from continuous experiments was high and the system proved very stable during the whole period of continuous operation. This indicates the high capacity of the microorganisms to adapt to variations of pollutant concentrations as well as an unexpected ability to survive in presence of relatively high feed concentrations. It does also prove the suitability of the novel monolith bioreactor to efficiently treat high pollutant loads.

Gas-phase bioreactors, as biofilters and biotrickling filters, are considered to operate under optimal conditions when the inlet pollutant-concentrations are below 4$5 \mathrm{~g} \mathrm{~m}^{-3}[2]$. Therefore, it is possible that sharper decreases in process efficiency could be observed in the monolith reactor for higher methanol concentrations, under otherwise constant operating conditions, although this was not confirmed experimentally.

A comparison of the elimination capacity reached in this study with those obtained by other researchers in the treatment of waste gases containing methanol clearly shows that the monolith bioreactor performs quite better than other conventional biofilters. Although methanol elimination capacities around $200 \mathrm{~g} \mathrm{~m}^{-3} \mathrm{~h}^{-1}$ have occasionally been reported in recent studies with conventional biofilters [27] and biotrickling filters [19], elimination capacities around $100 \mathrm{~g} \mathrm{~m}^{-3} \mathrm{~h}^{-1}$ are more usual in such systems [22], [28] and [29]. The good performance observed here with the monolith bioreactor may be due to the following reasons: (1) high mass transfer property of the monolith and (2) presence of an efficient acidotolerant microbial culture.

The conversion ratio of methanol to $\mathrm{CO}_{2}$ was slightly lower than the value found in batch assays and similar to others obtained by different authors. Similar recovery values have been obtained during studies on methanol elimination in a biofilter packed with lava rock, where $57.7 \pm 11.4 \%$ of the oxidized methanol was converted into carbon dioxide [27]. The theoretical number of moles of carbon dioxide that should be produced is equal to the moles of methanol eliminated when neglecting biomass growth. If biomass growth is accounted for, then 1 mole methanol would yield 0.55 mol carbon dioxide, according to Eq. (1), confirming that more than $90 \%$ of the carbon substrate was completely converted and mineralized.

It is also important to note that the biomass accumulation, as reflected in Fig. 7, had very little effect on methanol removal even at high values of the pressure drop. Physical operational problems are, however, encountered at such high pressures, necessitating backwashing to remove excess biomass. The pressure drop through a biofilter bed typically ranges from 10 to $100 \mathrm{~Pa} \mathrm{~m}^{-1}$, and some authors reported that it can go up to $1700 \mathrm{~Pa} \mathrm{~m}^{-1}$ in biofilters with porous media containing bulking agents [11]. Typical superficial gas velocities may vary from 5 to more than $500 \mathrm{~m}^{3} \mathrm{~m}^{-2} \mathrm{~h}^{-1}$ [1]. Overall, the monolith bioreactor showed a higher elimination capacity and low pressure drops compared to other conventional bioreactors, which could save on operation costs when the bioreactor is scaled up for application in the field. 
In summary, this study has demonstrated the potential of the monolith bioreactor, in terms of applications in the field of biotreatment of waste gases. The following conclusions can be drawn from the results presented in this study:

The yield coefficient of biomass on methanol is 0.345 , which is within the range of reported growth yields of acidophilic methanol utilizing bacteria and lower than the values of the neutrophilic microorganisms.

The maximum elimination capacity of methanol reached a value of $234 \mathrm{~g} \mathrm{~m}^{-3} \mathrm{~h}^{-1}$, while the removal efficiency remained above $80 \%$.

The amount of methanol recovered as carbon dioxide in the monolith reactor was $51 \%$ on a molar basis, proving that complete pollutant mineralization took place.

The bioreactor was found to readily support biomass growth on the high surface area of the monolith. High liquid flow rates could be used to easily remove excess biomass, and maintain the pressure drop around or below $6 \mathrm{~mm} \mathrm{H}_{2} \mathrm{O} \mathrm{m}^{-1}$ during long-term operation. However, even higher pressure drops of $25 \mathrm{~mm} \mathrm{H}_{2} \mathrm{O} \mathrm{m}^{-1}$ had very little effect on methanol removal.

Clogging of the channels was slow as a result of using a slow growing acidotolerant culture and, occasionally, a high liquid flow for washing.

\section{Acknowledgements}

The present research was financed by the Spanish Ministry of Education and Science (Project CTM2007-62700/TECNO) and through European FEDER funds. Yaomin Jin was financially supported through a project of the Xunta de Galicia (Project PGIDIT05PXIC10304PN). We owe special thanks to Rauschert Verfahrenstechnik $\mathrm{GmbH}$, Steinwiesen, Germany, for the generous gift of the monolith carriers. 


\section{References}

C. Kennes, F. Thalasso

Waste gas biotreatment technology

J Chem Technol Biotechnol, 72 (1998), pp. 303-319

C. Kennes, M.C. Veiga

Conventional biofilters

C. Kennes, M.C. Veiga (Eds.), Bioreactors for waste gas treatment, Kluwer Academic Publishers, Dordrecht/Boston/London (2001), pp. 47-98

C. Kennes, M.C. Veiga

Inert filter media for the biofiltration of waste gases-characteristics and biomass control

Rev Environ Sci Biotechnol, 1 (2002), pp. 201-214

O. Ariga, M. Kimura, M. Taya, T. Kobayashi

Kinetic evaluation and characterization of ceramic honeycomb-monolith bioreactor J Ferment Technol, 64 (1986), pp. 327-334

K.M. de Lathouder, T. Marques Fló, F. Kapteijn, J.A. Moulijn

A novel structured bioreactor: development of a monolithic stirrer reactor with immobilized lipase

Catal Today, 105 (2005), pp. 443-447

K. Kawakami, K. Adachi, N. Minemura, K. Kusunoki

Characteristics of a honeycomb monolith 3-phase bioreactor-oxidation of glucose by immobilized glucose-oxidase

Kagaku Kogaku Ronbunshu, 13 (1987), pp. 318-324

K. Kawakami, K. Kawasaki, F. Shiraishi, K. Kusunoki

Performance of a honeycomb monolith bioreactor in a gas-liquid solid three-phase system

Ind Eng Chem Res, 28 (1989), pp. 394-400

Y. Zhang, L. Han, J. Wang, J. Yu, H. Shi, Y. Qian

An internal airlift loop bioreactor with Burkholderia pickttii immobilized onto ceramic honeycomb support for degradation of quinoline

Biochem Eng J, 11 (2002), pp. 149-157

S. Ebrahimi, R. Kleerebezem, M.T. Kreutzer, F. Kapteijn, J.A. Moulijn, J.J. Heijnen, M.C.M. van Loosdrecht

Potential application of monolith packed columns as bioreactors, control of biofilm formation

Biotechnol Bioeng, 93 (2006), pp. 238-245

Y. Jin, M.C. Veiga, C. Kennes

Development of a novel monolith-bioreactor for the treatment of VOC-polluted air

Environ Technol, 27 (2006), pp. 1271-1277 
C. van Lith, G. Leson, R. Michelsen

Evaluating design options for biofilters

J Air Waste Manage Assoc, 47 (1997), pp. 37-48

E. Estévez, M.C. Veiga, C. Kennes

Biofiltration of waste gases with the fungi Exophiala oligosperma and Paecilomyces variotii

Appl Microbiol Biotechnol, 67 (2005), pp. 563-568

Y. Jin, M.C. Veiga, C. Kennes

Performance optimization of the fungal biodegradation of $\alpha$-pinene in gas-phase biofilter

Proc Biochem, 41 (2006), pp. 1722-1728

C. Kennes, M.C. Veiga

Fungal biocatalysts in the biofiltration of VOC-polluted air

J Biotechnol, 113 (2004), pp. 305-319

M.C. Veiga, M. Fraga, L. Amor, C. Kennes

Biofilter performance and characterization of a biocatalyst degrading alkylbenzene gases

Biodegradation, 10 (1999), pp. 169-176

H.D. Pöland, J. Sawistowsky, M. Jechorek, E. Schulze

High performance fermentation process using methanol utilizing bacteria

Acta Biotechnol, 11 (1991), pp. 303-314

B.T. Mohammad, M.C. Veiga, C. Kennes

Mesophilic and thermophilic biotreatment of BTEX-polluted air in reactors

Biotechnol Bioeng, 97 (2007), pp. 1423-1438

A.A. Chan

Attempted biofiltration of reduced sulfur compounds from a pulp and paper mill in northern Sweden

Environ Prog, 25 (2006), pp. 152-160

Y. Jin, M.C. Veiga, C. Kennes

Co-treatment of hydrogen sulfide and methanol in a single-stage biotrickling filter under acidic conditions

Chemosphere, 68 (2007), pp. 1186-1193

Y. Jin, L. Guo, M.C. Veiga, C. Kennes

Fungal biofiltration of $\alpha$-pinene: effects of temperature, relative humidity, and transient loads

Biotechnol Bioeng, 96 (2007), pp. 433-443

APHA

Standard methods for the examination of water and wastewater

(20th ed.)American Public Health Association, Washington, DC (1998) p. 4-178 
Z. Shareefdeen, B.C. Baltzis, Y.S. Oh, R. Bartha

Biofiltration of methanol vapor

Biotechnol Bioeng, 41 (1993), pp. 512-524

M. Luvsanjamba, B. Sercu, S. Kerstész, H. Van Langenhove

Thermophilic biotrickling filtration of a mixture of isobutyraldehyde and 2-pentanone

J Chem Technol Biotechnol, 82 (2007), pp. 74-80

M. Ericsson, L. Ebbinghaus, M. Lindblom

Single-cell protein from methanol-economic-aspects of the norprotein process

J Chem Technol Biotechnol, 31 (1981), pp. 33-43

M.H. Haggstrom, M. Dostalek

Growth of methylomonas-methanolica-factors influencing growth-yield

Eur J Appl Microbiol Biotechnol, 12 (1981), pp. 107-112

I.J. van der Klei, H. Yurimoto, Y. Sakai, M. Veenhuis

The significance of peroxisomes in methanol metabolism in methylotrophic yeast

Biochim Biophys Acta: Mol Cell Res, 1763 (2006), pp. 1453-1462

O.J. Prado, M.C. Veiga, C. Kennes

Treatment of gas-phase methanol in conventional biofilters packed with lava rock

Water Res, 39 (2005), pp. 2385-2393

S. Krailas, Q.T. Pham, R. Amal, J.K. Jiang, M. Heitz

Effect of inlet mass loading, water and total bacteria count on methanol elimination using upward flow and downward flow biofilters

J Chem Technol Biotechnol, 75 (2000), pp. 299-305

H. Yang, B. Minuth, D.G. Allen

Effects of nitrogen and oxygen on biofilter performance

J Air Waste Manage Assoc, 52 (2002), pp. 279-286 